\title{
Challenges Facing the Shift from the Conventional to Problem-Based Learning Curriculum
}

\author{
Waleed H. AlBuali ${ }^{1} \&$ Abdul Sattar Khan ${ }^{2}$ \\ ${ }^{1}$ Peadiatrics Department, College of Medicine, Imam Abdulrahman Bin Faisal University, Saudi Arabia \\ ${ }^{2}$ Family \& Community Medicine Department, College of Medicine, King Faisal University, Saudi Arabia \\ Correspondence: Dr. Abdul Sattar Khan, Family \& Community Medicine Department, College of Medicine, \\ King Faisal University, Saudi Arabia. E-mail: amkhan@kfu.edu.sa
}

$\begin{aligned} & \text { Received: December 11, } 2017 \quad \text { Accepted: December 29, } 2017 \quad \text { Online Published: February 6, } 2018 \\ & \text { doi:10.5539/hes.v8n1p36 }\end{aligned}$ URL: https://doi.org/10.5539/hes.v8n1p36

\begin{abstract}
Tremendous changes have taken place in medical curricula in the last two decades; these changes have arguably created some imbalances in the quality of medical graduates around the globe, which may be partly due to the number of resources often demanded by the design of the newer curricula. Therefore, resource-poor countries are often unable to adopt these newer models of training in their entirety and are thus compelled to follow the socalled "Subject-Based Curriculum". The authors have discussed and prepared some guidelines to provide direction for the adaptation and implementation of Problem-Based Learning Curriculum (PBLC) in countries with different cultures and limited resources. This article addresses the issues and concerns raised by medical educationists on the implementation of PBLC especially in developing countries. These pointers include practical solutions for such common problems as staff, cost, infrastructure and training.
\end{abstract}

Keywords: Problem Based Learning, Problem Based Learning Curriculum

\section{Introduction}

The implementation of Problem-Based Learning Curriculum (PBLC) in developing countries is still under lot of debate. Several reports give account of the failure of PBLC in the developing world. For instance, a case study of Rosario Medical School in Argentina (Carrera et al, 2003) concluded that medical schools should consider whether a PBL curriculum is even appropriate for them, and should be aware of the difficulties that lie ahead. Besides, uncertainties about the efficacy of PBL (Pasternack, 2003) make a case for exploring such alternatives to PBL as the hybrid curricula (Gold et al, 2004). To the best of our knowledge, there are no published studies that compare the cost-effectiveness of different curricula except one study with a hypothetical comparison that showed promising results in favor of PBLC (Hamdy \& Agamy, 2011). A discussion of the available research on curriculum implementation specifically in developing countries may help medical schools to take better decisions on the kind of curricula to implement (Chan, 2009). However, available literature at present does not provide helpful advice to medical schools with limited resources to effectively implement PBLC.

These guidelines are based on the personal experience of the authors who belonged to a college where a curriculum was adopted from University of Groningen, Netherlands, as well as a detailed literature search. In 2012, after decision of change of the curriculum from traditional to PBL format, we adopted the PBL curriculum from University of Groningen. First, we developed the competencies and program learning outcome based on strategy plan of King Faisal University' vision and mission and also matched it with National Competence Framework and SaudiMed (Zaini et al, 2011). We considered the following steps for adaptation of the curriculum.

1. Need Assessment

2. A list of International or national universities offering PBL was generated

3. Develop a committee for review of available curriculum and visited 4 - national \& 4 - international places to compare and contrast all PBL curriculum

4. The pros and cons of partial versus complete adoption of curriculum that was discussed in a focus group meeting 
5. A matrix of scoring system was developed in keeping mind the requirements of our students based on cultural norms. Identification of 16 items (1-5 Weightage Scale) for comparison among different curricula (Table no.1).

6. After processing all data from the different universities, all items were scored by the committee. The total score was calculated using the initial matrix (Table no.1).

7. The College Board observed facilities and educational arrangements, conducted face to face discussion with faculty and students

8. The English language was selected as a mandatory criterion, preferably a foreign university or college program, with participation of Saudi students.

9. Delegates from such universities were invited at college of medicine, King Faisal University for presentation

Table 1. Selection of Curriculum Decision Matrix

\begin{tabular}{|c|c|c|}
\hline S. No & Items & Weightage based on Scale 1 to 5 \\
\hline 1. & Visited site, viewed facilities \& resources & \\
\hline 2. & English available now & \\
\hline 3. & Detailed Blocks were seen & \\
\hline 4. & Web site material to us & \\
\hline 5. & Updating of content freely & \\
\hline 6. & Double qualification & \\
\hline 7. & Middle exit degree & \\
\hline 8. & Local Problems \& topics & \\
\hline 9. & Examination Bank to us & \\
\hline 10. & Easy communication & \\
\hline 11. & Readiness to cooperate & \\
\hline 12. & Help in NCAAA documents & \\
\hline 13. & Good training program & \\
\hline 14. & Easy availability, Training & \\
\hline 15. & International schools & \\
\hline 16. & Cost + other materials & \\
\hline
\end{tabular}

The institution where the authors worked and currently work is in the midst of a major change from the traditional 'subject-based', teacher-centric curriculum to a 'problem-based' curriculum. The first author had experiences worked at other universities for planning to adopt PBL curriculum. The second author had experience in different countries including Pakistan, Turkey, Yemen, and Saudi Arabia for working for the implementation of the PBL curriculum. Besides, the practical experiences, authors have attended many trainings for PBL, have qualifications from renowned universities in the world and already published research papers on medical education. Therefore, authors' experiences during this change have helped to formulate these guidelines highlighted as different challenges as follows:

\subsection{Challenge 1: Rationale for the Huge Student Intake}

The developing countries, which defined as ecumenical struggling and not have enough budget to spend on specialized educational system (UNO, 2012). In these countries, medical schools (especially those funded by the government) usually tend to have a large intake of students often in the range of 300 to 400per year (Boulet et al, 2007). Therefore, dividing the large number into small groups for problem-based learning presents logistical issues (Hendry et al, 2003). The rationale behind this large intake is mainly to offset the lack of primary care doctors and to narrow the gap between demand and supply. However, it is important to consider restricting the intake so that quality is not unduly compromised at the expense of numbers. The suggestion, therefore, is that colleges reduce the intake by using more valid and reliable admission criteria that focus not only on knowledge but also aptitude \& emotional quotient (EQ) (Wagner et al, 2001). An intake of 200 students per year would be the optimum for an effective implementation of PBLC. Moreover, the acceptable number of students recommended for a small group should be no more than twelve.

\subsection{Challenge 2: Judicious Use of Space}

The other major issue highlighted in many studies (Carrera et al, 2003, Wagner et al, 2001, Liuzzi, 2011) is the requisite space for the conduct of the PBL sessions. Logistics, especially in laboratories, is a major issue even in 
medical colleges specially designed for PBL. Temporary distribution of small groups for the same activity allows fewer facilitators to handle all the students by repeating required instructions. Hypothetically, for 200 medical students, at least 20 small rooms are needed for the conduct of PBL, an impossible luxury for any public medical school in any developing countries. The suggestion is that each tutor takes multiple groups in the year .For example, instead of 8 tutors for 8 groups in one particular year, the number of tutors can be halved if four tutors took 2 groups each in two separate sessions. This reduces the required net square feet assigned for instructional space.

\subsection{Challenge 3: Efficacious Use of Available Audiovisual Aids}

Another issue of resources is audiovisual aids required for all PBL session. The cost of a single system for each PBL room might sometimes be unaffordable. A few rooms could be equipped with the electronic audiovisual devices, and the remaining rooms have such manual devices as markers, flipcharts, and white boards. It should be noted that simple flip charts and white boards are just as effective for the PBL learning process. Students should be encouraged to develop their power-point presentation skills but should avoid getting dependent on power points. It is suggested that students use flip charts as far as possible for the brain storming and presentation sessions and consider the use of PowerPoint for sessions that involve the entire group, such as response sessions or group presentations (Harrison, 2013). Even if Power Point presentation is obligatory , one computer could be connected to a cable with several outlet screens in every room and controlled by one computer operator.

\subsection{Challenge 4: Leading Change Management}

The faculty who have been involved for several years in subject-based curriculum need to be retrained to become a part of PBLC. There are two options: A critical mass of faculty should be developed by giving them the opportunity to observe and participate in PBLC activities. The training of this cohort can be done either off-site in a college that practices PBLC or by on-site with experts. It is crucial for a critical mass of trained faculty to be built in advance to ensure a smooth transition to the new curriculum. Faculty training should focus not only on the concepts of medical education but also general management, leadership and change management. The initial phases of curriculum change are understandably fraught with anxiety on the part of both faculty and students. It is essential to bring all stakeholders on board in order to implement change effectively. Regular refresher courses should be planned as changes in the mind-set take time. Sensitizing the faculty and students is crucial for the success of any new curriculum, and is often one of the most difficult issues in the implementation process (Kiguli-Malwadde et al, 2006).

\subsection{Challenge 5: Recruitment of Extra Staff}

The extra staff required for PBLC is a major issue for any developing country that wants to adapt its curriculum to PBLC. Even if intake into the medical school is reduced to 200, at least 20 tutors are required at a time to conduct PBL sessions. However, a recent study (Hamdy \& Agamy, 2011) shows that although the cost of two strategies was similar, the educational roles and the faculty engagement in education in a PBL curriculum is broader than in the traditional curriculum. Another option would be to include such components as case-based learning and team- based learning which require fewer faculty members to handle large groups. Team -based learning is especially useful for the preparation of students before they embark on proper PBL activity (Abdelkhalek et al, 2010).

Furthermore, we suggest that interns are used for this. During the one-year internship, students can be used on rotation bases for the conduct of PBL sessions. They do need training, but this can be done by the trainers. Non-medical staff might be used as tutors - lab technicians could run intermittent 'self- running sessions' based on pre-listed cues and other lab sessions also made more 'problem based' (Kaliyadan et al, 2012). Tutor-less PBL sessions is a possibility and peer to peers tutoring can be utilized in the senior classes like the $4^{\text {th }}$ year or final year.

\subsection{Challenge 6: Minimizing the Cost}

Several reports indicate (Donner, 1990; Finucane et al, 2009) that expenditure for salaries of faculty and related costs constitute a major part of the recurring budget of the medical college. The concept of high cost of PBL (Albanese \&Mitchell, 1993) is denied in a recent study (Hamdy \& Agamy, 2011) which states that PBL does not necessarily require an increase in the number of faculty. This study further states that the time spent by faculty on educational activities in the two curriculum models is similar. In addition, as suggested, a reduction of student intake, the judicious use of available space, and efficacious use of equipment diminishes to a large extent the high cost for implementation of PBLC. 


\subsection{Challenge 7: Handling the Information Overload and Continuing the PBL Process throughout the Course}

There is invariably, the complaint of information load especially in the initial years of PBLC. Therefore, what is recommended is, a larger span of PBL sessions and the selection of important cases only for the development some basic knowledge. PBL sessions within clinical postings could be run later e.g., For students (small group) in a 3- week rotation in dermatology, 6-8 hours of the total contact hours should be kept for at least 2 PBL cases specifically related to dermatology. This would ensure the continuation of the PBL process throughout the medical course with no extra strain on the faculty (Kaliyaden et al, 2012).

\subsection{Challenge 8: Clear Priorities}

The goals of the curriculum should be clear. It is important to ensure that the focus on a PBL curriculum, does not shift to a hybrid system in which the faculty end up doing all the work of a traditional subject- based curriculum - lectures and labs, plus the PBL sessions which places an additional burden on them. On the other hand, if the plan is to incorporate some PBL elements, the number of PBL sessions/time devoted to PBL should be limited. It has been shown that Hybrid PBL curricula can degenerate into dysfunctional curricula inferior even to the traditional approach from which PBL emerged. Therefore, schools should have a proper program evaluation system and a quality assurance system to inspect their curriculum periodically for signs of dysfunction for a timely corrective action to be taken. A decision to convert fully to standard PBL is probably more cost feasible, but requires more inputs in terms of time, expertise and commitment, which is only possible with supportive leadership (Lim, 2012).

\subsection{Challenge 9: Standardization of Prior Knowledge}

The criteria for entrance into medical college in developing countries varies, but are mostly based on the same subjects (Khan, 2012) learned in high school .This does not necessarily ensure that the readiness of students for the activation of their prior knowledge for PBLC. In addition, since students may have come from a variety of high schools with different curricula, there could be much disparity among the students. A short preparatory program of 2-3 months during which students are given broad concepts related to the knowledge, skills and attitudes required for the PBLC might be a good idea. It should be stressed that the idea is not to burden the students or faculty with detailed didactic lectures, but to give students a feel of what to expect in PBLC. The preparatory program should be kept as simple and conceptually based as possible.

\subsection{Challenge 10: Motivation for Self-Directed Learning}

The self-directed learning is directly related to resources available at institutions and accessible to all medical students. There are two issues in developing countries: the lack of resources and a disinclination towards self-directed learning (SDL). In addition, is the need for a change in the attitude of the faculty from the teacher -centered learning to student- centered learning. Self-directed learning should percolate through all activities including lectures and practical sessions. Faculty should be encouraged to give broad concepts rather than detailed knowledge during lectures and practical sessions. Resources like library facilities and books are essential for self-directed learning. Many publishers have schemes in which books (both hard-copies and soft-copies) can be obtained at subsidized rates for developing countries (HINARI, 2012; British Library, 2012). It is suggested these options be explored and more focus placed on online resources for the present generation of medical students even in the developing countries since young people are becoming increasingly tech-savvy. During the initial stages of curriculum implementation, it may sometimes be difficult for students to directly switch to a self-directed mode of learning since they have been used to a teacher -centered model throughout their schooling. This is particularly so in many developing countries where independent learning is not particularly encouraged in schools. It is suggested, therefore, that the initial focus should be on 'directed -self learning' in which groups of students are placed under a mentor who can sit with them and help them grasp the self-learning process better. The students can be gradually weaned off the mentorship in the course of a few months when the students are deemed capable of complete independent self-learning.

\subsection{Challenge 11: Assessment}

The assessment of PBLC could also be an issue for both faculty and students. The knowledge part of PBL could be incorporated into the broader assessment by including more questions based on the tutorials in the final exam of the module. This reduces the assessment load specific to PBL. Restrict the PBL specific assessment to assessment of generic skills. The importance of the assessment of generic skills and professional behavior communication skills, reflection and collaboration should be stressed to both students and faculty. These generic skills should carry a significant weight in the assessment scheme, so structured checklists should be used whenever possible to make the assessment of these skills more objective. 


\subsection{Challenge 12: Development of Cases}

The faculty can definitely try to write their own cases, but proper case writing requires a good team effort. Admittedly, it is difficult to assemble an effective team at the initial stages of the implementation of the new curriculum (Mpofu et al, 1997). The PBL cases are crucial for the success of the program. Poorly designed cases that do not address higher thinking may jeopardize the entire learning process (Azer et al, 2012). It is suggested that in the initial phase, pre-written cases can be modified to local contexts and used. The next step is for a team to write cases to be sent to an external expert for review and gradual implementation. Of course, it goes without saying that if the faculty is well trained and confident, there is absolutely no harm in preparing cases locally (Weiss, 2003).

\section{Conclusion}

The authors based on their experiences and literature review concluded that many countries want to adopt the PBL curriculum, however, they have fear in order to implement it because of the different myths relevant to high demands of logistics, manpower and money for its proper execution. Though it seems challenging but there are several solutions mentioned in the article for the properly implementation of the PBL curriculum. Which conclude that it is possible to implement PBL curriculum even in limited resources.

\section{References}

Abdelkhalek, N., Hussein, A., Gibbs, T., \& Hamdy, H. (2010). Using team-based learning to prepare medical students for future problem-based learning. Med Teach., 32, 123-129. https://doi.org/10.3109/01421590903548539

Albanese, M. A., \& Mitchell, S. (1993). Problem-based learning: a review of literature on its outcomes and implementation issues. Acad Med., 68, 52-81. https://doi.org/10.1097/00001888-199301000-00012

Azer, S. A., Peterson, R., Guerrero, A. P., \& Edgren, G. (2012). Twelve tips for constructing problem-based learning cases. Med Teach., 34, 361-367. https://doi.org/10.3109/0142159X.2011.613500

British Library. (2013). British library for developmental studies: resources for developing country researchers [online]. Available: http://blds.ids.ac.uk/about-us/resources-for-research/resources-for-developing-country-researchers

Boulet, J., Bede, C., Mckinley, D., \& Norcini, J. (2007). An overview of the world's medical schools. Med Teach., 29, 20-26. https://doi.org/10.1080/01421590601131823

Carrera, L. I., Tellez, T. E., \& D'ottavio, A. E. (2003). Implementing a problem-based learning curriculum in an Argentinean medical school: implications for developing countries. Acad Med., 78, 798-801. https://doi.org/10.1097/00001888-200308000-00010

Chan, L. C. (2009). Factors affecting the quality of problem-based learning in a hybrid medical curriculum. Kaohsiung J Med Sci., 25, 254-257. https://doi.org/10.1016/S1607-551X(09)70070-1

Country Classification. United Nations. (2012). Retrieved from http://www.un.org/en/development/desa/policy/wesp/wesp_current/2014wesp_country_classification.pdf. Accessed date [06/01/2018]

Donner, R. S., Bickey, H. (1990). Problem-based learning: an assessment of its feasibility and costs. Human Pathol., 21, 881-885. https://doi.org/10.1016/0046-8177(90)90170-A

Finucane, P. M., Shannon, W., \& McGarth, D. (2009). The financial costs of delivering problem-based learning in a new, graduate-entry medical program. Med Educ., 43, 594-598. https://doi.org/10.1111/j.1365-2923.2009.03373.x

Gold, J. P., Begg, W. B., Fullerton, D., Mathisen, D., Olinger, G., Orringer, M., \& Verrier, E. (2004). Successful implementation of a novel internet hybrid surgery curriculum: the early phase outcome of thoracic surgery prerequisite curriculum e-learning project. Ann Surg., 240, 499-507; discussion 507-9. https://doi.org/10.1097/01.sla.0000137139.63446.35

Harrison, F. (2008). Using learning resources to enhance teaching and learning [online]. London deanary. Retrieved from http://www.faculty.londondeanery.ac.uk/e-learning/small-group-teaching/using_learning_resources_to_enha nce_teaching_-_learning.pdf [accessed 15 april 2017].

Hendry, G. D., Ryan, G., \& Harris, J. (2003). Group problems in problem-based learning. Med Teach., 25, 609-16. https://doi.org/10.1080/0142159031000137427 
HINARI. (2013). Access to research in health programme. Retrieved from http://www.who.int/hinari/about/en/ [accessed 15 april 2013].

Hamdy, H., \& Agamy, E. (2011). Is running a problem-based learning curriculum more expensive than a Traditional subject-based curriculum? Med Teach., 33, e509-e514. https://doi.org/10.3109/0142159X.2011.599451

Kaliyadan, F., Amri, M., Dhufiri, M., Amin, T. T., \& Khan, M. A. (2012). Effectiveness of a modified tutorless problem-based learning method in dermatology - a pilot study. J Eur Acad Dermatol Venereol, 26, 111-113. https://doi.org/10.1111/j.1468-3083.2011.04016.x

Khan, A. S. (2012). Medical entrance examination pattern needs tweaking! J Pak Med Assoc., 62, 627.

Kiguli-Malwadde, E., Kijjambu, S., Kiguli, S., Galukande, M., Mwanika, A., Luboga, S., \& Sewankambo, N. (2006). Problem based learning, curriculum development and change process at faculty of medicine, Makerere University, Uganda. Afr Health Sci., 6, 127-130.

Lim, W. K. (2012). Dysfunctional problem-based learning curricula: resolving the problem. BMC Med Educ., 12, 89. https://doi.org/10.1186/1472-6920-12-89

Liuzzi, F. (2011). Looking back on problems encountered in problem-based learning. Clin Teach., 8, 202-203. https://doi.org/10.1111/j.1743-498X.2011.00455.x

Mpofu, D. J. S., Das, M., Murdoch, J. C., \& Lanphear, J. H. (1997). Effectiveness of problems used in problem-based learning. Med Educ., 31, 330-334. https://doi.org/10.1046/j.1365-2923.1997.00672.x

Pasternack, A. (2003). Does problem-based learning solve the problems of medical education?. Duodecim, 119, 2017-2019.

Wagner, P. J., Jester, D. M., \& Moseley, G. C. (2001). Use of the emotional quotient inventory in medical education. Acad Med., 76, 506-507. https://doi.org/10.1097/00001888-200105000-00035

Weiss, R. E. (2003). Designing problems to promote higher-order thinking. New Dir Teach Learn, 95, 25-31. https://doi.org/10.1002/tl.109

Zaini, R. G., Bin, Abdulrahman, K. A., Al-Khotani, A. A., Al-Hayani, A. M. A., Al-Alwan, I. A., \& Jastaniah, S. D. (2011). Saudi Meds: a competence specification for Saudi medical graduates. Medical teacher, 33(7), 582-584. https://doi.org/10.3109/0142159X.2011.578180

\section{Copyrights}

Copyright for this article is retained by the author(s), with first publication rights granted to the journal.

This is an open-access article distributed under the terms and conditions of the Creative Commons Attribution license (http://creativecommons.org/licenses/by/4.0/). 